\title{
Knowledge, punitive attitudes and punitive gap: Finnish findings
}

\author{
Juha Kääriäinen ${ }^{1}$ (D)
}

Published online: 3 May 2018

(C) The Author(s) 2018

\begin{abstract}
The aim of this study was to examine the empirical connections of three phenomena among the Finnish population: (1) the level of knowledge on the crime situation and the criminal justice system; (2) the general punitive attitude and (3) sentence decisions in certain concrete crime cases using vignettes. The same vignettes were shown to professional judges to study the punitive gap between laypeople and judges. The research subjects are a representative sample of the population $(N=1251)$ and district court judges $(N=192)$. The research resulted in four main findings: (1) a higher level of knowledge among laypeople mitigates their punitive attitudes, (2) information included in the case vignettes is associated with the sentence decisions of laypeople in different ways, depending on the characteristics of the case; punitive gap varies greatly, (3) level of knowledge is, in general, a poor predictor for the severity of the sentence decisions of laypeople and (4) the general punitive attitude is, at best, a weak predictor for the severity of sentence decisions of laypeople. In conclusion, laypeople's decisions are probably affected partly by the same legal factors as the professional judges' decisions and partly by attitudes that are expressly related to features of the cases in question.
\end{abstract}

Keywords Knowledge $\cdot$ Punitive attitude $\cdot$ Punishment $\cdot$ Sentencing

\section{Introduction}

In recent years, there has been a rather lively debate among scholars about the role of public opinion when deciding on the direction of crime policy and, in particular, the severity of penalties (see e.g. Ryberg and Roberts 2014). Populist politicians prefer simple surveys, but researchers ask if there is a danger of the justice system losing its credibility if laypeople's opinions are not adequately heard (Robinson 2014; Roberts 2014). One part of this debate concerns the methods of opinion polls. We get different results on the attitudes of the

Juha Kääriäinen

juha.kaariainen@helsinki.fi

1 Institute of Criminology and Legal Policy, University of Helsinki, Aleksanterinkatu 40, 00014 Helsinki, Finland 
population depending on what methods we use. The result of simple attitude queries is usually that people consider the punitive practice of their country to be excessively lenient and, when asked for their opinion, propose that the severity of punishments should be increased. For example, according to the European Social Survey carried out in 2010, 69\% of Europeans believe that "people who break the law should be given much harsher sentences than they are these days." "

The general understanding of a strong punitive attitude in the population at large is a myth. The key argument in this discussion has been that the punitive attitude of people decreases considerably if they receive sound information about the state of crime in their country and how the criminal justice system functions (e.g. Roberts et al. 2012). It has been found that the level of punitive reactions of people falls when a concrete criminal case vignette is presented for them and they are asked to give an appropriate sentence decision about it (see e.g. Balvig et al. 2015). In this case, the information included in the vignettes and the given sentence options appear to reduce the punitive tendency.

However, it seems that the discussion on the level of knowledge, punitive attitudes and sentence decisions are mixed in an awkward way. The purpose of this study wass to try to keep these concepts separate from each other and examine the empirical connections between them: What are the actual connections between a general level of knowledge on the crime situation and the criminal justice system in a country and the punitive attitudes and sentence decisions of laypeople in certain concrete crime cases described in vignettes?

This research was carried out in Finland, which can be considered a country of relatively liberal crime policies. Over the last few decades, Finland has tried to avoid, in particular, unconditional prison sentences and to develop rehabilitative community sanctions. As a result of this policy, Finland's prison rates are one of the lowest compared with other European countries and other continents (Lappi-Seppälä 2011). At the same time, international comparisons show that Finns' confidence in their justice system is very high (see e.g. Jackson et al. 2014).

\section{Attitudes to punishment and knowledge}

An attitude can be understood as the tendency to view a concrete issue or phenomenon either positively or negatively (see e.g. Albarracin et al. 2014). Attitudes on a population level are usually interpreted through opinion surveys where the respondents express their opinions about some concrete assertions. Punitive attitudes are measured either through individual variables in the manner of the above example or by developing different scales of punitiveness (e.g. Hartnagel and Templeton 2008; Hogan et al. 2005).

These general indicators of punitive attitudes, however, often embody the problem in which penal sanctions may have several different objectives, which people might emphasise in different ways (see e.g. de Keijser et al. 2007; Oswald et al. 2002; Weiner et al. 1997). First, based on the retributive justification of punishment, we discuss how society has a right and duty to punish lawbreakers to ensure that the victim of a crime receives moral restitution for the violation of his/her rights. This is perhaps the most common and traditional way to justify punishment. Someone found guilty of a crime deserves to be punished, and he/she must pay

\footnotetext{
$\overline{{ }^{1} \text { Based on online analysis of ESS }}$ round 5, see http://nesstar.ess.nsd.uib.no/webview/.
} 
the victim and society for his/her deed by undergoing punishment. Next, we discuss functions that aim to use punishment to prevent future crimes:

A punishment may protect society by isolating the offender from society for a certain time period. This can be called the objective of incapacitation through punishment.

A punishment may also be a deterrent because awareness of the consequences of a deed will reduce the desire of someone to commit a crime.

Through penal sanctions, one can also try to influence the behaviour of an offender or the factors behind that behaviour, such as a drug problem. In the latter case, a factor behind a drug problem is rehabilitation of an offender.

During punishment, efforts are made to influence the individual factors behind the behaviour of committing a crime.

Finally, we discuss the restorative aims of the sanction system. Those aims are not so much punishment but correction of damage caused by crimes and the resolution of social conflicts to avoid problems in the future.

When the way people view the different aims of punishment are studied empirically, all the above aims are considered important; they are complementary rather than contradictory (Doble 2002). However, when studying the aims of punishment among Dutch students and judges, de Keijser et al. (2002) found that those aims form two mutually independent dimensions, which they call harsh treatment and social constructiveness. The former combines retributive, incapacitative and deterrent goals, and the latter targets the principles of rehabilitation and restoration. It is noteworthy, therefore, that these are punishment-related goals that are mutually independent: People might consider both harsh treatment of offenders and its effective rehabilitation to be important. When examining attitudes, this means that researchers must distinguish between actual punitive attitudes and attitudes concerning the rehabilitation of offenders (see also McKee and Feather 2008). In other words, we must consider that, when demanding punishment, people might expect it to fulfil both punitive and rehabilitative functions.

What socio-economic factors have been connected to people's punitive attitudes? Results regarding gender, age and income level are contradictory, and when connections between these variables are found, they have been quite loose (see e.g. Maruna and King 2009; Roberts and Indermaur 2007). A low level of education seems to explain the desire to punish. This result seems to repeat regularly from one study to another (see e.g. Maruna and King 2009; Roberts and Indermaur 2007; Roberts et al. 2012). The impact of education on mitigating punitive attitudes also seems to be connected to the fact that people generally have quite poor knowledge about crime and the workings of the criminal justice system (Hough et al. 2013). Many studies have shown that the punitive attitudes of people decrease in severity the more they know about how the criminal justice system operates and about the alternatives for punishment (Balvig et al. 2015; Gelb 2008; Roberts et al. 2012). One possible reason for this is that the key source of information about such matters for ordinary people is the media, which often highlights exceptionally serious crime cases and in a way that prejudges the punishments handed out for crimes (Roberts and Doob 1990). It can also be assumed that the significance of the media as an information source regarding crime and punishment is heightened among those who are less educated (Rosenberger and Callanan 2011). 


\section{Sentencing decisions and the punitive gap}

In this article, the first research question concerns connections in Finnish data between knowledge of crime and the criminal justice system and punitive attitudes: Is the level of people's knowledge about crime and punishment associated with the variation in their punitive attitudes?

The picture of the general punitive attitude of people changes if, in opinion surveys, respondents are given information about crimes and their sanctions. Instead of asking about general attitudes regarding punishments, some concrete crime cases can be described to respondents, who can be asked to choose a punishment from a given set of alternatives. In that way, the respondent gets closer to the situation in which courts find themselves when imposing punishments. This is then a question of studying decision making rather than attitudes (Green 2006). The respondent to a questionnaire or interview is put in the position of a lay judge and, based on the source data given, must decide the punishment to be imposed for a crime (e.g. de Keijser and Elffers 2009; Gelb 2008; Hough and Roberts 1999). Source data expressly provide information on the case in question based on what decision must be made.

The scope of the vignettes in these kinds of studies is limited. Usually, a description of the incident is given, such as an assault case. The description clarifies the level of seriousness of the offence, which can be described, for example, in terms of how it was committed, weapons used or extent of any injuries inflicted. The description might also clarify events and circumstances preceding the deed, which might explain, for example, the chain of events, motives of the perpetrator and contribution of the victim to the events. Such descriptions often also provide information about the socio-demographic features of the victim and the offender. In addition, laypeople are usually told about punishment alternatives from which a professional judge will make his/her choice.

One problem remains: scarcity of information about the actual decision-making process of courts. In population surveys, it is not possible to provide all the information about complex criminal cases that judges receive and need. In any case, the result of such studies has been that information about a crime and alternatives for sanctions bring participants' decisions closer to a real decision-making practice than would have been the case from attitude surveys. Based on previous research, it seems undeniable that the so-called punitive gap between punishments issued by laypeople and professional judges decreases when laypeople are provided with information about the crime and the choice of punishments in this way (Gelb 2008; Hough and Roberts 1999). In the literature, discussion is principally focused on how great this impact is and whether the punitive gap can be completely bridged when a sufficient amount of information is provided. For example, de Keijser et al. (2007) found that very detailed information concerning a case reduced the punitive gap but was unable to eliminate it completely. Researchers who carried out a study in Switzerland noted that in verdicts given by laypeople and professional judges based on the normal vignette method, no great difference was observed. Moreover, in the case of one type of crime - fraud-laypeople tended to give an even more lenient sentence than professional judges (Kuhn 2002). Research carried out in the Nordic countries that applied the focus-group method addition to the vignette method found that by providing detailed information, the punitive gap could be bridged (Balvig et al. 2015).

Our second research question asks: What is the association between the information included in case vignettes and the sentence decisions of laypeople? In other words, how wide 
is the punitive gap between laypeople and professional judges in Finland, and how much variation is there in the size of the punitive gap between the different vignettes?

As previously stated, many studies have found that people's knowledge about the nature of the problem of crime in their own society and the criminal justice system is very poor. It has also been found that a low level of knowledge results in hardened punitive attitudes (e.g. Hough and Roberts 1999). There are very few studies that apply the vignette method to determine how general knowledge about crime and punishment affects the decision-making process of laypeople. Information contained in vignettes probably affects decisions regarding punishment in a way that reduces sentences. However, what significance does the respondent's general level of knowledge of a crime and the workings of criminal law have on his/her sentence decision in a certain individual case? This question is important, bearing in mind that raising people's level of knowledge could reduce the punitive gap (Indemaur and Hough 2002).

This leads us to our third research question: Do higher levels of knowledge about crime and punishment reduce the severity of punishments that are imposed based on vignettes? In other words, by raising the general level of knowledge of the population, can the punitive gap between laypeople and professional judges be reduced?

Our fourth research question asks about the relationship between punitive attitudes and the sentence decisions issued by laypeople. Do punitive attitudes predict the desire of laypeople to punish?

Studies that apply the vignette method tend to mix up attitudes and sentence decisions. Researchers often use sentence decisions to determine laypeople's punitive attitudes (see e.g. Balvig et al. 2015; Roberts et al. 2012). It is possible, even probable, that someone with a strong punitive attitude will impose tougher punishments in a research situation than someone with a more liberal attitude towards punishment in principle. We can claim that the sentence decisions of laypeople are mainly based on factors other than their punitive attitudes. The idea of the vignette method is for respondents to assume the role of a judge in a research situation - to impose punishment considering the presented facts. Respondents might then understand that, when making decisions, a judge must keep his/her own attitudes separate from the facts and the legal provisions. On average, a layperson has poor knowledge of the provisions of the criminal code regarding, for example, the essential elements or scales of punishment for specific crimes. Facts indicating the severity of the offence as well as the other characteristics or conditions under which the offence was committed will probably weigh heavily in the sentence decisions of laypeople. General punitive attitudes would then be less important than attitudes towards crimes that are the subject of the description in the vignette and circumstances surrounding those crimes. Such a crime might be, for example, sexual violence. As an example case, a woman is raped in her apartment after an evening in a bar. When reading a description of this rape case, even a person with a high punitive attitude might think that the case was not very serious because the victim should have taken better care of herself, drunk less alcohol or avoided taking the man she had met in the bar back to her apartment. Correspondingly, someone with a very liberal punitive attitude might think that rape is a very serious crime under any circumstances.

\section{Research questions}

The research questions of this article are as follows:

1. What is the association between the level of knowledge of crime and the criminal justice system and punitive attitude? 
2. What is the association between information included in case vignettes and the sentence decisions of laypeople?

3. Is a layperson's knowledge about crime and punishment associated with the severity of punishment that he/she imposes based on vignettes?

4. What is the relationship between the punitive attitudes of laypeople and the sentence decisions they make?

\section{Data and methods}

\section{Vignettes}

When planning the research, we began from the premise that the choice of vignettes would reflect social discussion that has been prevalent in Finland in recent years regarding the reprehensibility of different crimes and the problems that may arise in sentencing practice. The vignettes prepared for the study thus describe the following incidents (in parentheses, we give the name of the offence according to the criminal code for a genuine case, upon which the vignette is based, if it differs from what is given here):

- Street violence (aggravated assault)

- Child sexual abuse

- Rape

- Intimate partner violence (assault)

- Smuggling and sale of drugs (aggravated drug offence)

- Tax fraud (aggravated tax fraud)

- Drunken driving (aggravated drunken driving).

The vignettes are based on real cases, mainly from 2012, relating to all the abovementioned types of offences. Researchers created the final texts for the vignettes, in which no legal terms were used that might have prompted respondents. For example, official names for crimes given in the criminal code were not used so that they would not lead respondents to use penal scales specified in law. To a certain extent, we had to invent factors when describing circumstances of the case, because court materials were scarce. The vignettes can be found in the published project report: https://helda.helsinki.fi/handle/10138/232414.

\section{Population survey}

The population survey was performed in spring and early summer 2016 using computerassisted personal interviews (CAPI) in Finnish and Swedish. The interviewer used a tablet computer and showed the answer choices to the respondent on the tablet. A total of 38 interviewers participated in the fieldwork. The sample was drawn up by quota sampling so that the sample would be representative of respondents' places of residence, ages and genders. A total of 1251 interviews were carried out in the research. For analysis, weighting coefficients were calculated and used to adjust data to correspond to the distribution of respondents' regions, ages, genders and political views. Data adjusted by weighting coefficients also corresponded well with the educational structure of Finns. Respondents could select an option indicating the severity of punishment for each type of punishment: for example, an option 
related to the amount of a fine or the length of a prison sentence. The interviewer showed the answer choices on a screen, and respondents also received answer choices on a separate card.

\section{Survey of judges}

The survey of judges was carried out at the same time as the population interviews and consisted of an online questionnaire using the Unipark programme. The Ministry of Justice gave the researchers the names of senior district court judges and information about how many judges there were. The questionnaire was sent by e-mail to the registry offices and chancelleries of district courts and to senior judges, so they could be forwarded to all district court judges. In the message, they were told about the aims of and arrangements for the study in which, based on the given vignettes, the judges would be asked to specify a punishment in accordance with prevailing legal practice. Legal notaries were excluded from the survey. After 2 weeks, a reminder e-mail was sent, and the period for providing a response was extended. It was possible to answer the questionnaire in either Finnish or Swedish. According to information given by the Ministry of Justice, there were 496 district court judges and senior judges at the time of carrying out the survey. The survey received 192 accepted responses, representing $39 \%$ of all district court judges. The survey of judges used exactly the same vignettes that were used in the population survey.

\section{Variables and analysis}

In both the judges' questionnaire and the population interviews, respondents chose from a selection of alternative punishments for each offence. Therefore, there was a need to calculate variables indicating the severity of the sentence in both data sets in a harmonised way so that each respondent's choice could be placed in one of the following categories:

1. Waiving of sentence.

2. Fine, no other punishment.

3. Conditional imprisonment or conditional imprisonment + fine; no other punishment.

4. Community service: If community service was imposed together with conditional or unconditional imprisonment, it was coded as community service.

5. Surveillance penalty: If a surveillance penalty was imposed together with conditional or unconditional imprisonment, it was coded as a surveillance penalty. If both a surveillance penalty and community service were imposed, it was coded as a surveillance penalty.

6. Imprisonment or imprisonment + fine: Length of imprisonment was less than 1 year.

7. Imprisonment or imprisonment + fine: Length of imprisonment was 1 year to 2 years 11 months.

8. Imprisonment or imprisonment + fine: Length of imprisonment was 3 years or more.

In the population interviews, a set of ten statements concerning the crime situation and punishments imposed for crimes in Finland were presented to respondents. There were two response choices: correct and incorrect. A variable indicating the level of knowledge was calculated by adding together the number of correct answers in this quiz. The statements were as follows:

1. Property crime has increased in Finland in recent years (incorrect). 
2. Violent crime has increased in Finland in recent years (incorrect).

3. The number of Finns who die annually in road traffic accidents is about 2.5 times greater than the number of victims of homicide (correct).

4. The proportion of violent crimes to all crimes in Finland is less than $10 \%$ (correct).

5. The victims and perpetrators of homicides usually do not know each other beforehand (incorrect).

6. In Finland, a conditional or unconditional prison sentence is almost always imposed for aggravated assault (correct).

7. A typical Finnish prisoner is a man with alcohol and drug problems (correct).

8. Community penalties reduce reoffending more effectively than custodial sentences (correct).

9. An unconditional prison sentence is almost always imposed for aggravated rape (correct).

10. Homicides are committed less in countries with more severe penalties (incorrect).

After the quiz, every fifth respondent was also told the correct answers, which were justified briefly either by showing statistical patterns on separate cards containing facts related to the answers or by verbally describing their content. For the purposes of analysis, a dummy variable was formed to indicate whether or not the respondent had received additional information.

The variable concerning punitive attitudes was formed as follows. Respondents were asked the question: "Criminal sanctions means punishments imposed for different crimes and other measures that may be related to them. What kind of objectives should sanctions have, in your opinion?" Mark your answer on a scale of 0 to 10 , where 0 means that the objective is not at all important and 10 means that, in your opinion, the objective is very important.

Options, which were presented to respondents in a random order, are shown in Table 1. Variables were run using principal component analysis, and a two-factor solution (as shown in Table 1) was the result. Interpretation seems quite clear: The first factor reflects the respondents' attitudes towards rehabilitation and the second towards punitive elements. Factor scores were calculated for both factors, and these scores indicate each respondent's attitude towards both rehabilitation and punishment. This study used only the latter variable.

Table 1 Goals of sentencing; principal component analysis

\begin{tabular}{lrr}
\hline & Component \\
\cline { 2 - 3 } & Method 1 & Method 2 \\
\hline Giving a warning example & .167 & .664 \\
Rehabilitation of offenders & .807 & -.110 \\
Socialising offenders & .669 & .138 \\
Giving retribution for offenders & .238 & .501 \\
Training and educating offenders & .830 & -.125 \\
Maintaining general respect for the law & .517 & .487 \\
Replacing the financial and health losses suffered by victims & .488 & .386 \\
Isolating dangerous criminals from society & .038 & .652 \\
Promoting understanding and reconciliation between victims and perpetrators & .534 & .077 \\
\hline
\end{tabular}

Extraction method: principal component analysis, Rotation method: Varimax with Kaiser normalisation 
This study used questions concerning socio-demographic information: gender, age, level of respondent education and the level of respondent household income.

\section{Results}

\section{Knowledge and punitive attitudes}

For our first research question "What is the relationship between punitive attitudes and people's level of knowledge about crimes and the penal system? Does ignorance increase people's desire to punish?" Figure 1 shows the average levels of punitive attitudes according to the level of respondent knowledge. It clearly shows that as the level of knowledge increases, punitive attitude decreases in a linear manner. By calculating the regression model, we can take into account the impact of the respondent's gender, age, level of income and level of education on the link between variables. A variable of additional information was also included in the analysis. Of the background variables, respondent gender and education seemed to have an independent significance in the formation of a punitive attitude, with the result that men are more punitive than women and education reduces punitiveness. However, even holding these factors as constant, level of knowledge does seem to have a strong link to punitive attitude. We also found that offering additional information in the interview did not have a statistically significant impact on punitive attitude (see Table 2).

\section{Punitive gap}

Our second research question concerns the punitive gap: "Are the sentence decisions of laypeople more severe than those of professional judges in all vignettes, or is there variation in the wideness of the gap?" In other words: "What is the association between information included in the case vignettes and the sentence decisions of laypeople?" Figure 2 shows the severity of sentencing on a case-by-case basis by measuring the average choice of type of punishment on a scale of $1-8$, where $1=$ waiving of sentence and $8=$ unconditional

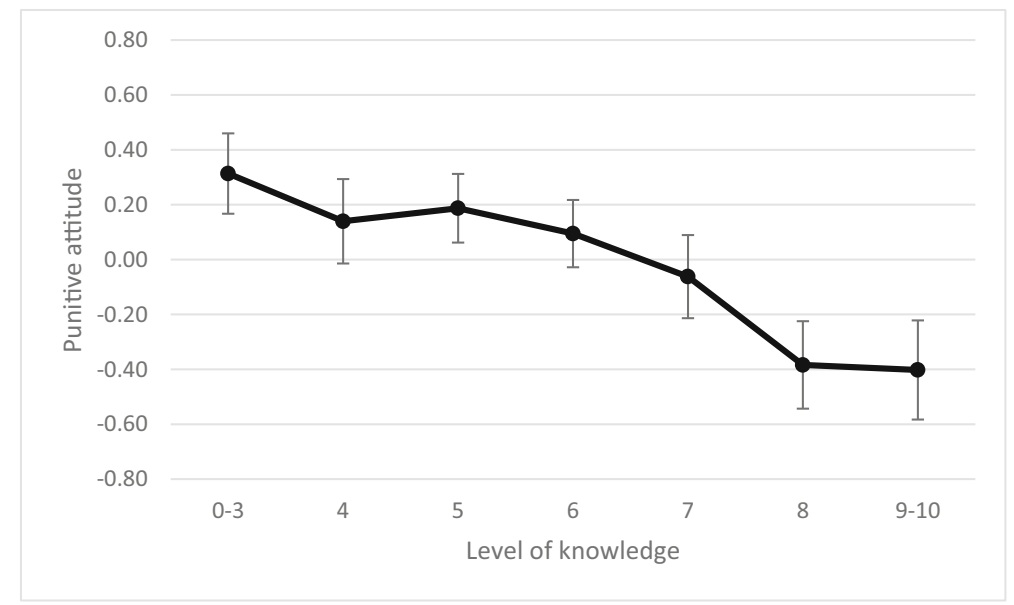

Fig. 1 Punitive attitude: means with $95 \%$ confidence intervals (CI) by level of knowledge 
Table 2 Predictors of punitive attitudes using standardised (beta) regression coefficients $p<0.05 ; * *=p<0.01 ; * * *=p<$ 0.001

\begin{tabular}{lc}
\hline Variable & Statistics \\
\hline Male & $0.079 * *$ \\
Age & 0.022 \\
Income & -0.02 \\
Education & $-0.094^{* *}$ \\
Knowledge & $-0.203^{* * *}$ \\
Information & -0.05 \\
$R^{2}$ (adj.) & 0.07 \\
\hline
\end{tabular}

imprisonment of 3 years or more (see description of variables above). The cases have been organised in the diagram based on severity of the decision issued by professional judges.

Firstly, in five of the seven offences, laypeople judged more severely than judges if the type of punishment is used as an indicator of severity. The largest difference is in the case of intimate partner violence, and the second largest difference is in the case of drunken driving. In two cases, the penal practice chosen by the judges is, however, more severe than those selected by laypeople in terms of the type of punishment. The difference is greatest in the case dealing with tax fraud. However, in the case concerning drug smuggling, the penal practice chosen by judges was only slightly more severe than that of laypeople. We can therefore say that the punitive gap varies considerably. Whereas for some crimes the gap is clear, for others, it is less so. There are also cases in which judges are more severe than laypeople.

Secondly, we can examine the severity of sentences in terms of length of unconditional imprisonment. This examination is meaningful only for five offences, as judges only very rarely imposed unconditional imprisonment in cases of intimate partner violence and drunken driving; this occurred just once in the former case and seven times in the latter. The results for the five other offences are compiled in Table 3. In all five cases, judges imposed longer sentences than laypeople. Measured in this way, direction of the gap changed. Judges were more severe than laypeople. Moreover, if we look at the distributions of answers, we find that, especially among laypeople, dispersion of the answers is rather large.

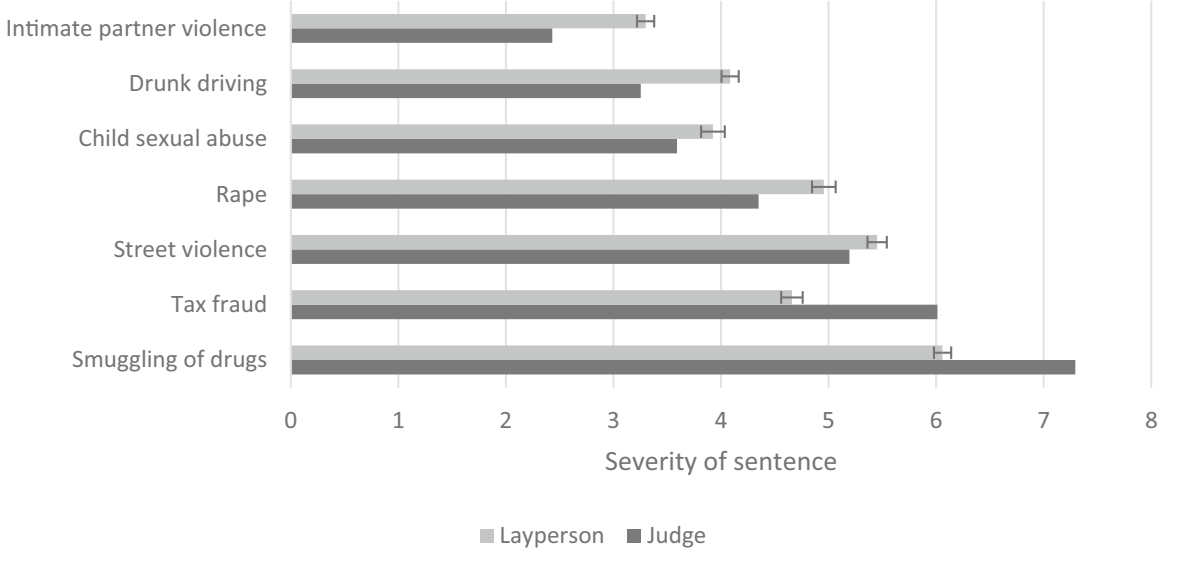

Fig. 2 Severity of sentences in seven crime cases by laypeople and judges 


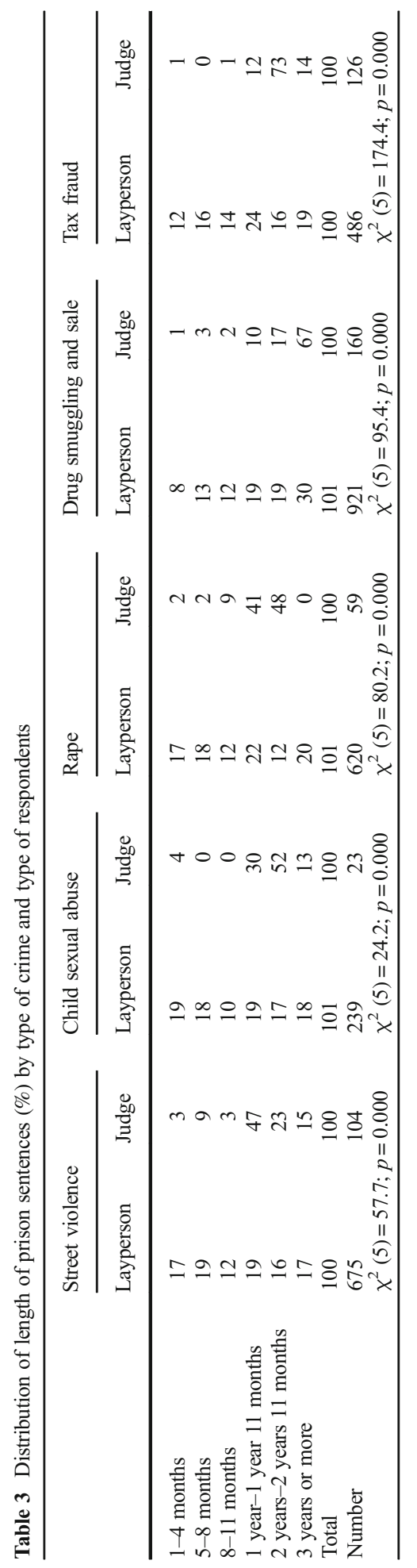




\section{Knowledge and severity of punishments}

We stated above that knowledge reduces punitive attitude. Another question is: "What impact does the level of knowledge have on the sentence decisions of laypeople? Does a person's knowledge of crime and the penal system reduce the severity of his/her sentence decisions?" Figure 3 shows the average punishments imposed by laypeople (on a scale of 1-8) for each offence according to level of knowledge.

Generally speaking, level of knowledge and severity of punishment are not connected or have only a minor connection. Regarding the offences of street violence and drug smuggling, knowledge seems to reduce the severity of punishment slightly. However, for sexual abuse of children, the connection is the opposite: knowledge seems to increase the severity of punishment. We see an indication that the possible weak connection between these two variables is nonlinear rather than linear. As knowledge increases, the desire to punish first decreases slightly, then rises again at the point where the level of knowledge is highest of all.

In Fig. 3, it was not sensible to mark the statistical CIs for average levels of punishment in order to maintain even moderate clarity. The connections between these two variables are weak and, owing to the size of the data set, CIs are quite long, so it is not easy to find statistically significant differences. To refine results, however, we can calculate the regression models for each type of offence so that severity of punishment is set as a dependent variable, and level of knowledge and additional information shared in the interview are set as independent variables.

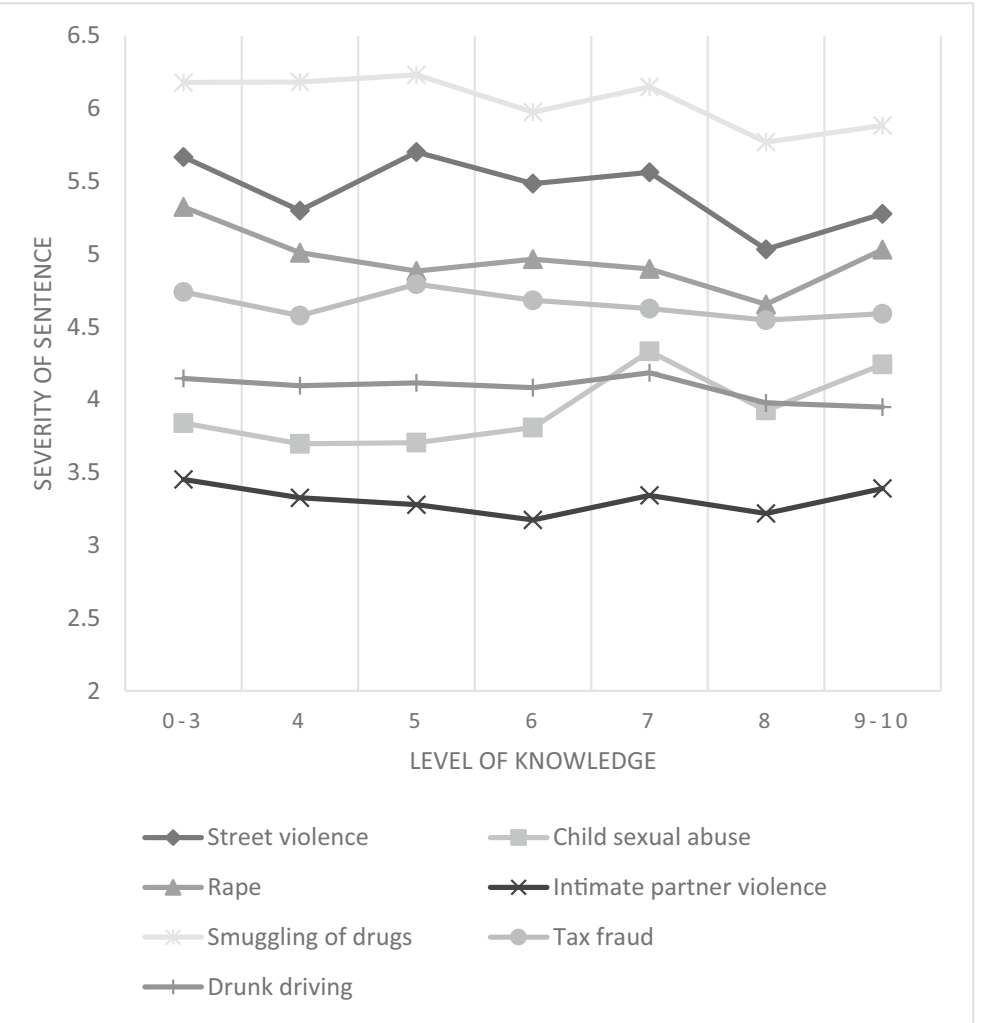

Fig. 3 Severity of sentence by level of knowledge and type of crime 
At the same time, we can standardise the same key socio-economic factors as above, where we examined the relationship between punitive attitudes and sentencing decisions.

Table 4 shows these regression models. From the results, we notice the same things we were already able to conclude in Fig. 3: knowledge reduces the severity of punishment in only one case: people who impose a slightly more lenient punishment for street violence are those whose knowledge of crime and punishment is better than others. In one case, the reverse is true: level of knowledge seems to increase severity of the sentence decision in the case of child sexual abuse. It is also interesting to note that age seems to have a connection with the severity of punishment in three cases: young people demand a more severe penalty for rape than old people do, but the situation is the reverse for drug smuggling and tax fraud.

\section{Punitive attitudes and the severity of punishments}

Finally, the fourth research question: "What is the connection between punitive attitudes and sentence decisions? Do punitive attitudes increase the severity of punishments?"

Figure 4 shows the connections between severity of punishment and punitive attitudes for each offence. We can see that punitive attitudes seem to have a connection to the three or four decisions in which more severe sentences were imposed: decisions concerning the smuggling of drugs, street violence, rape and tax fraud. Correspondingly, it seems that punitive attitudes do not have any impact on the severity of punishment imposed for less reprehensible cases. If we calculate regression models in a similar way as above (see Table 5), our result is confirmed. In the case of some offences considered more serious, punitive attitudes seem to affect the sentence decision in a statistically significant way, but this association does not apply in all cases. Overall, the connection between punitive attitudes and sentence decisions seems surprisingly minor.

\section{Summary and conclusions}

The general aim of this study was to examine empirical connections of three phenomena among the Finnish population: (1) the level of knowledge on the crime situation and criminal justice system; (2) the general punitive attitude; (3) sentence decisions of laypeople in certain concrete crime cases. The first research question addressed the association between level of knowledge of crime and the criminal justice system and punitive attitude. The finding was expected: The less people know about these matters, the more severe their punitive attitude. This result confirms many previous observations (see e.g. Balvig et al. 2015; Roberts and Hough 2011), so it does not merit further attention here.

Table 4 Knowledge and information as predictors of sentence severity using standardised regression coefficients

\begin{tabular}{lclllllr}
\hline & $\begin{array}{l}\text { Street } \\
\text { violence }\end{array}$ & $\begin{array}{l}\text { Child sexual } \\
\text { abuse }\end{array}$ & Rape & $\begin{array}{l}\text { Intimate partner } \\
\text { violence }\end{array}$ & $\begin{array}{l}\text { Drug } \\
\text { smuggling }\end{array}$ & $\begin{array}{l}\text { Tax } \\
\text { fraud }\end{array}$ & \multicolumn{1}{c}{$\begin{array}{l}\text { Drunk } \\
\text { driving }\end{array}$} \\
\hline Male & $0.08^{*}$ & $0.08^{*}$ & -0.02 & 0.01 & 0.00 & 0.04 & -0.01 \\
Age & 0.03 & 0.02 & $-0.26^{* * *}$ & -0.05 & $0.14^{* * *}$ & $0.13^{* * *}$ & 0.06 \\
Income & -0.03 & -0.03 & 0.04 & -0.05 & $-0.08^{*}$ & $0.08^{*}$ & -0.02 \\
Education & 0.02 & -0.02 & 0.03 & -0.03 & $-0.08^{*}$ & $-0.13^{* * *}$ & -0.04 \\
Knowledge & $-0.07^{*}$ & $0.10^{* *}$ & -0.03 & -0.01 & -0.04 & 0.00 & 0.01 \\
Information & -0.01 & -0.01 & -0.02 & -0.04 & 0.02 & 0.02 & -0.06 \\
$R^{2}$ & 0.01 & 0.02 & 0.07 & 0.01 & 0.04 & 0.05 & 0.01 \\
\hline
\end{tabular}




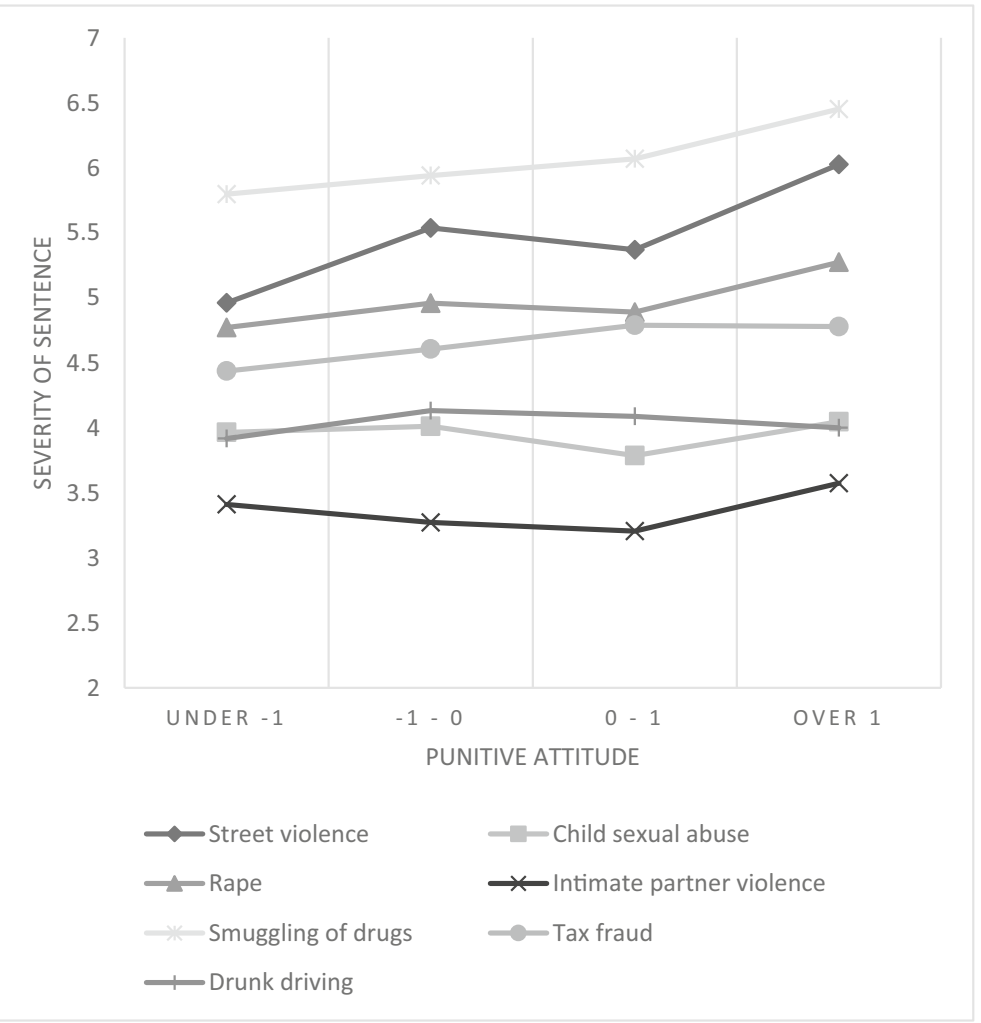

Fig. 4 Severity of sentence by levels of punitive attitudes and types of crime

Our second question was about information included in case vignettes and its connection to sentence decisions. We found that the punitive gap between sentence decisions of laypeople and professional judges varied considerably depending on case. Information about an offence therefore affected sentence decisions of laypeople in very different ways depending on the given information. In this respect, discussion about whether there was a punitive gap between public opinion and penal practice (see e.g. de Keijser et al. 2007) seemed to be rather misleading. Instead of asking whether there is a punitive gap, we should ask how information on features of crimes, perpetrators or victims are connected to the scope or direction of the punitive gap.

Table 5 Punitive attitude as a predictor of severity of sentence using standardised regression coefficients

\begin{tabular}{|c|c|c|c|c|c|c|c|}
\hline & $\begin{array}{l}\text { Street } \\
\text { violence }\end{array}$ & $\begin{array}{l}\text { Child sexual } \\
\text { abuse }\end{array}$ & Rape & $\begin{array}{l}\text { Intimate partner } \\
\text { violence }\end{array}$ & $\begin{array}{l}\text { Drug } \\
\text { smuggling }\end{array}$ & $\begin{array}{l}\text { Tax } \\
\text { fraud }\end{array}$ & $\begin{array}{l}\text { Drunk } \\
\text { driving }\end{array}$ \\
\hline Male & $0.07 *$ & $0.09 *$ & -0.03 & 0.00 & -0.01 & 0.03 & -0.02 \\
\hline Age & 0.02 & 0.03 & $-0.26^{* * *}$ & -0.04 & $0.15^{* * *} *$ & $.013 * * *$ & 0.06 \\
\hline Income & -0.02 & -0.03 & 0.04 & -0.05 & $-0.08^{*}$ & $-0.07 *$ & -0.03 \\
\hline Education & 0.03 & 0.01 & 0.03 & -0.04 & -0.07 & -0.11 & -0.04 \\
\hline $\begin{array}{l}\text { Punitive } \\
\text { attitude }\end{array}$ & $0.18 * * *$ & 0.00 & $0.11 * *$ & 0.02 & $0.11 * *$ & $0.08^{*}$ & 0.01 \\
\hline$R^{2}$ & 0.04 & 0.01 & 0.08 & 0.01 & 0.05 & 0.05 & 0.01 \\
\hline
\end{tabular}

$*=p<0.05 ; * *=p<0.01 ; * * *=p<0.001$ 
When studying sentence decisions made by professional judges, legal and extra-legal factors in sentencing have been distinguished from each other (see e.g. Sporer and Goodman-Delahunty 2009). The former are those originating from the criminal code and other official norms, and the latter are those connected to unconscious attitudes and prejudices. Legal factors vary by jurisdiction, but the criminal code and other regulations are usually determined by characteristics, scales of punishment and factors of an offence, which must be considered when deciding on the severity of punishment.

It can be assumed that in research when applying the vignette method, the share of the extra-legal factors in the decision-making process of laypeople is greater than in that of professional judges. In these situations, laypeople are in no way bound by laws and other official norms that should or should not be considered when determining punishment. Naturally, laypeople also do not understand legislation or the prevailing punitive practices to the same extent as professional judges do.

However, we can assume that laypeople will intuitively apply the same general legal principles as judges do to their sentence decisions - for example, that the punishment must be in proportion to the dangerousness and harmfulness of the offence or to how consciously the perpetrator committed the act. We can also assume that laypeople will intuitively understand at least some of the aggravating circumstances for an offence prescribed in law (e.g. the planned nature of the offence or the offender's previous criminal record) and the grounds for mitigation or principles of equity (e.g. the offender's young age or a settlement reached between offender and victim), which are referred to in the Finnish Criminal Code. In relation to this, however, there is much yet to research. Surprisingly little research has been conducted on laypeople's understanding of the grounds for the mitigation of punishment or the principles of equity (see e.g. Roberts and Hough 2011, 2013).

The third question of our study was regarding laypeople's level of knowledge about crime and punishment and its connection to the severity of punishment that he/she imposes based on vignettes. The level of knowledge about crime and punishment had a very minor connection to the sentence decisions. Level of knowledge even increased the probability of harsh decisions in some cases. This result may be a consequence of what we observed above. The sentence decisions made by laypeople are determined by legal and extra-legal factors connected to the case itself and not by the general level of knowledge. Information included in the case seemed to be a more important factor than general criminological erudition.

This observation is in line with what we found regarding connections between general punitive attitudes of laypeople and the sentence decisions they made, which was the fourth study question. Namely, we found that, to some extent, a general punitive attitude is connected with harsher sentences concerning certain but not all cases. The connection appeared to be relatively minor if it was evident at all.

We can therefore argue that the impact of attitudes on sentence decisions should not be studied only generally in terms of punitive attitude. Attitudes may affect people's decisions in different ways - sometimes aggravating and sometimes mitigating them depending on the object to which the attitude is attached. For example, people's understanding of the dangerousness and harmfulness of an offence may differ from how legislation and sentencing practice formed over time sees them. People usually consider violence more dangerous than financial loss (Stalans 2002). Our observations in this research also indicate that laypeople imposed a much more lenient sentence for tax fraud than judges did (see also Kuhn 2002). With regard to sexual crimes, laypeople may have great differences of opinion about the seriousness of offences. These differences concern attitudes towards gender roles. Angelone et al. (2015) found that those with a positive attitude towards traditional gender roles considered rape occurring between people who know each other to be less serious and imposed a more lenient punishment than those whose attitude towards traditional gender roles was 
negative. It might also be that laypeople do not recognise or accept all the grounds for increasing the severity of or mitigating punishment, which are written in law (see e.g. Roberts and Hough 2011, 2013).

In addition, extra-legal factors may have a considerable impact on the sentence decisions of laypeople. Observations using the vignette method might vary considerably depending on the character of the victims or offenders regarding background, gender, profession and other factors concerning social position. In this sense, the question of the general punitive attitudes of laypeople, or whether or not there is a punitive gap, might be much too general to be answered. Rather than studying general punitive attitudes or the punitive gap, we should examine in a more detailed way factors that affect sentence decisions of laypeople: To what extent are decisions based on shared views of the legal grounds for punishment, and to what extent are they based on different attitudes and preconceptions?

Much more research is needed to confirm our findings, and as the research was carried out in Finland, it may be possible that the relationships between these concepts would be different in other countries. We can also take a critical look at how this study has measured the level of general knowledge or punitive attitudes. Hopefully, the debate on this topic will continue and the results refined.

Acknowledgments The author wishes to thank the anonymous reviewers for their helpful responses to and suggestions for this article.

Funding This work was supported by the Ministry of Justice of Finland.

Open Access This article is distributed under the terms of the Creative Commons Attribution 4.0 International License (http://creativecommons.org/licenses/by/4.0/), which permits unrestricted use, distribution, and reproduction in any medium, provided you give appropriate credit to the original author(s) and the source, provide a link to the Creative Commons license, and indicate if changes were made.

\section{References}

Albarracin, D., Johnson, B. T., \& Zanna, M. P. (Eds.). (2014). The handbook of attitudes. New York and London: Psychology Press.

Angelone, D. J., Mitchell, D., \& Grossi, L. (2015). Men's perceptions of an acquaintance rape: The role of relationship length, victim resistance, and gender role attitudes. Journal of Interpersonal Violence, 30(13), 2278-2303.

Balvig, F., Gunnlaugsson, H., Jerre, K., Tham, H., \& Kinnunen, A. (2015). The public sense of justice in Scandinavia: A study of attitudes towards punishments. European Journal of Criminology, 12(3), 342-361.

de Keijser, J. W., \& Elffers, H. (2009). Cross-jurisdictional differences in punitive public attitudes? European Journal on Criminal Policy and Research, 15(1-2), 47-62.

de Keijser, J. W., van der Leeden, R., \& Jackson, J. L. (2002). From moral theory to penal attitudes and back: A theoretically integrated modeling approach. Behavioral Sciences \& the Law, 20(4), 317-335.

de Keijser, J. W., Van Koppen, P. J., \& Elffers, H. (2007). Bridging the gap between judges and the public? A multi-method study. Journal of Experimental Criminology, 3(2), 131-161.

Doble, J. (2002). Attitudes to punishment in the US - Punitive and liberal opinions. In J. V. Roberts \& M. Hough (Eds.), Changing attitudes to punishment. Cullompton, Devon: Willan Publishing.

Gelb, K. (2008). Myths and misconceptions: Public opinion versus public judgment about sentencing. Federal Sentencing Reporter, 21(4), 288-290.

Green, D. A. (2006). Public opinion versus public judgment about crime. British Journal of Criminology, 46(1), $131-154$.

Hartnagel, T., \& Templeton, L. (2008). Perceptions, emotions and experiences of crime: Effects on attitudes toward punishment in a Canadian sample. In H. Kury (Ed.), Fear of crime-Punitivity. New developments in theory and research. Bochum: Universitätsverlag Brockmeyer. 
Hogan, M. J., Chiricos, T., \& Gertz, M. (2005). Economic insecurity, blame, and punitive attitudes. Justice Quarterly, 22(3), 392-412.

Hough, M., \& Roberts, J. V. (1999). Sentencing trends in Britain: Public knowledge and public opinion. Punishment \& Society, 1(1), 11-26.

Hough, M., Bradford, B., Jackson, J. et al. (2013). Attitudes to sentencing and trust in justice: Exploring trends from the crime survey for England and Wales. Ministry of Justice Analytical Series 2013. Available at: http://eprints.bbk.ac.uk/5195/1/5195.pdf. Accessed 8 Feb 2017.

Indemaur, D., \& Hough, M. (2002). Strategies for changing public attitudes to punishment. In J. Roberts \& M. Hough (Eds.), Changing attitudes to punishment: Public opinion, crime and justice (pp. 198-214). Cullompton, Devon: Willan Publishing.

Jackson, J., Kuha, J., Hough, M. et al. (2014). Trust and legitimacy across Europe: A FIDUCIA report on comparative public attitudes towards legal authority. Available at: http://eprints.lse.ac.uk/50650/. Accessed 8 Dec 2016.

Kuhn, A. (2002). Public and judicial attitudes to punishment in Switzerland. In J. V. Roberts \& M. Hough (Eds.), Changing attitudes to punishment: Public opinion, crime and justice. Cullompton, Devon: Willan Publishing.

Lappi-Seppälä, T. (2011). Explaining imprisonment in Europe. European Journal of Criminology, 8(4), 303-328.

Maruna, S., \& King, A. (2009). Once a criminal, always a criminal? 'Redeemability' and the psychology of punitive public attitudes. European Journal on Criminal Policy and Research, 15(1-2), 7-24.

McKee, I. R., \& Feather, N. T. (2008). Revenge, retribution, and values: Social attitudes and punitive sentencing. Social Justice Research, 21(2), 138-163.

Oswald, M. E., Hupfeld, J., Klug, S. C., et al. (2002). Lay-perspectives on criminal deviance, goals of punishment, and punitivity. Social Justice Research, 15(2), 85-98.

Roberts, J. V. (2014). Clarifying the significance of public opinion for sentencing policy and practice. In J. Ryberg \& J. Roberts (Eds.), Popular punishment: On the normative significance of public opinion. New York: Oxford University Press.

Roberts, J. V., \& Doob, A. N. (1990). News media influences on public views of sentencing. Law and Human Behavior, 14(5), 451-468.

Roberts, J. V., \& Hough, M. (2011). Custody or community? Exploring the boundaries of public punitiveness in England and Wales. Criminology \& Criminal Justice, 11(2), 181-197.

Roberts, J. V., \& Hough, M. (2013). Sentencing riot-related offending: Where do the public stand? British Journal of Criminology, 53, 234-256.

Roberts, L. D., \& Indermaur, D. (2007). Predicting punitive attitudes in Australia. Psychiatry, Psychology and Law, 14(1), 56-65.

Roberts, J. V., Hough, M., Jackson, J., et al. (2012). Public opinion towards the lay magistracy and the sentencing council guidelines: The effects of information on attitudes. British Journal of Criminology, 52(6), 1072-1091.

Robinson, P. H. (2014). The proper role of Community in Determining Criminal Liability and Punishment. In J. Ryberg \& J. Roberts (Eds.), Popular punishment: On the normative significance of public opinion. New York: Oxford University Press.

Rosenberger, J. S., \& Callanan, V. J. (2011). The influence of media on penal attitudes. Criminal Justice Review, $36(4), 435-455$.

Ryberg, J., \& Roberts, J. V. (2014). Exploring the normative significance of public opinion for state punishment. In J. Ryberg \& J. Roberts (Eds.), Popular punishment: On the normative significance of public opinion. New York: Oxford University Press.

Sporer, S. L., \& Goodman-Delahunty, J. (2009). Disparities in sentencing decisions. In M. E. Osvald, S. Bieneck, \& J. Hupfeld-Heinemann (Eds.), Social psychology of punishment of crime (pp. 379-401). Location: John Wiley \& Sons.

Stalans, L. J. (2002). Measuring attitudes to sentencing. In J. V. Roberts \& M. Hough (Eds.), Changing attitudes to punishment: Public opinion, crime and justice (pp. 128-147). Cullompton, Devon: Willan Publishing.

Weiner, B., Graham, S., \& Reyna, C. (1997). An attributional examination of retributive versus utilitarian philosophies of punishment. Social Justice Research, 10(4), 431-452. 